\title{
ALFARERÍA CON IMPRONTAS DE HOJAS POR TÉCNICA DE RESERVA EN LA PATAGONIA NOROCCIDENTAL ARGENTINA Y CENTRO-SUR DE CHILE. EXPERIMENTACIÓN, ASPECTOS ESTILÍSTICOS E HIPÓTESIS FUNCIONALES
}

\author{
POTTERY WITH LEAF IMPRINTING USING THE RESERVE TECHNIQUE IN \\ NORTHWESTERN PATAGONIA, ARGENTINA AND SOUTH CENTRAL CHILE. \\ EXPERIMENTATION, STYLISTIC ASPECTS AND FUNCTIONAL HYPOTHESES
}

\author{
Alberto Pérez ${ }^{1}$, Verónica Reyes ${ }^{2 *}$ y Luis Hermann ${ }^{3}$
}

\begin{abstract}
Se describe un estudio experimental tendiente a esclarecer si algunas de las modificaciones superficiales conocidas como improntas de hojas en negativo presentes en vestigios de alfarería encontradas recientemente en San Martín de los Andes, Argentina y también en la región Centro-Sur de Chile, aunque en esta última ampliamente documentadas, constituyen una modalidad estilística singular o son el resultado involuntario del proceso de cocción de las vasijas cerámicas. Los resultados refuerzan a la primera hipótesis, mientras que la segunda no pudo ser demostrada. De esta manera, consideramos a las evidentes improntas de hojas negativas como una modalidad estilística y a la técnica de manufactura como "reserva".
\end{abstract}

Palabras claves: alfarería, Patagonia Noroccidental, improntas negativas de hojas, reserva, arqueología experimental.

This paper describes an experimental approach developed in order to determine if the surface modifications known as negative-leaf imprints found on archaeological pottery from recently excavated sites at San Martin de los Andes, Argentina well-documented throughout South Central Chile were the result of an artistic choice or an inadvertent by-product of the firing process. Our results support the first hypothesis over the second. Thus we conclude that these negative-leaf imprints represents a stylistic tool developed by the Southern Andean pottery artists and the manufacturing technique as a type of "reserve".

Key words: Pottery, Northwestern Patagonia, negative imprint of leaves, reserve, experimental archeology.

La alfarería con pintura resistente (Rye 1981) o técnica negativa (Castro y Varela 1990), tanto del tipo pintado como aquella que presenta improntas de hojas en negativo, ha sido históricamente registrada en la vertiente occidental de la cordillera de los Andes y más recientemente en ámbitos lacustres boscosos de la provincia de Neuquén (Pérez y Reyes 2009) (Figura 1). Esta técnica fue asignada como parte de los elementos fósiles guías del complejo alfarero más temprano del sur de Chile, conocido como "complejo Pitrén" (Aldunate 1989; Dillehay 1990). En los contextos chilenos Pitrén las vasijas que presentan improntas de hojas en negativo (técnica resistente), por lo general, carecen en su superficie de algún tipo de engobe o pigmento, o sea, son monócromas, siendo aplicada la técnica resistente sobre el color original de la arcilla con que fueron manufacturadas las vasijas (Pérez y Reyes 2009). En cuanto a la disposición de las hojas sobre la superficie de las piezas, hay vasijas en las cuales sólo se observan hojas en la superficie exterior, mientras que en otras éstas se registran por la cara externa e interna. Algunas vasijas poseen abundancia de improntas distribuidas por toda la pieza, mientras que otras sólo las manifiestan en ciertos sectores, muchas veces en áreas del cuerpo cercanas al asa (Pérez y Reyes 2009).

Por su parte, las vasijas pintadas con técnica resistente presentan diseños geométricos compuestos por líneas, puntos o campos, generalmente dispuestos

\footnotetext{
Universidad de Buenos Aires, Buenos Aires, Argentina. arqueo.meliquina@gmail.com

Domo Consultores. Vic. Mackenna 7255. Of. 1105. La Florida. Santiago, Chile. *autor correspondiente: vreyesalvarez@vtr.net Proyecto Arqueológico Lanín-Colloncura, San Martin de los Andes, Prov. de Neuquén, Argentina. arqueo.meliquina@gmail.com
} 
sobre superficies que previamente fueron engobadas con rojo (Adán y Alvarado 1999). Además, los motivos geométricos aparecen aplicados exclusivamente en las categorías jarros, ya sea simétricos o asimétricos, lo cual también marca una importante diferencia con las vasijas que poseen improntas de hojas en negativo, ya que ellas se registran dentro de una amplia gama de tipos morfológicos. Pese a estas diferencias, existe una innegable cercanía tecnológica entre la aplicación de la pintura negativa que dio origen a los diseños geométricos Pitrén, con aquel proceso de manufactura que necesariamente debió ser usado para obtener improntas de hojas en negativo, presentes en vasijas tanto de sitios Pitrén chilenos como de contextos de ámbitos lacustres boscosos de la provincia de Neuquén, Argentina (Figura 1). En otros trabajos ya hemos puesto de manifiesto nuestra idea de que varias manifestaciones culturales observadas en el registro arqueológico de los ambientes lacustres boscosos de la Patagonia Noroccidental Argentina y el Centro Sur de Chile son producto de un espacio ecológico y culturalmente compartido por las mismas sociedades (Pérez y Reyes 2009). Estas manifestaciones compartidas cobrarían mayor "visibilidad arqueológica" en tiempos alfareros, facilitado por el carácter duradero de los soportes utilizados para expresar las singularidades de sus

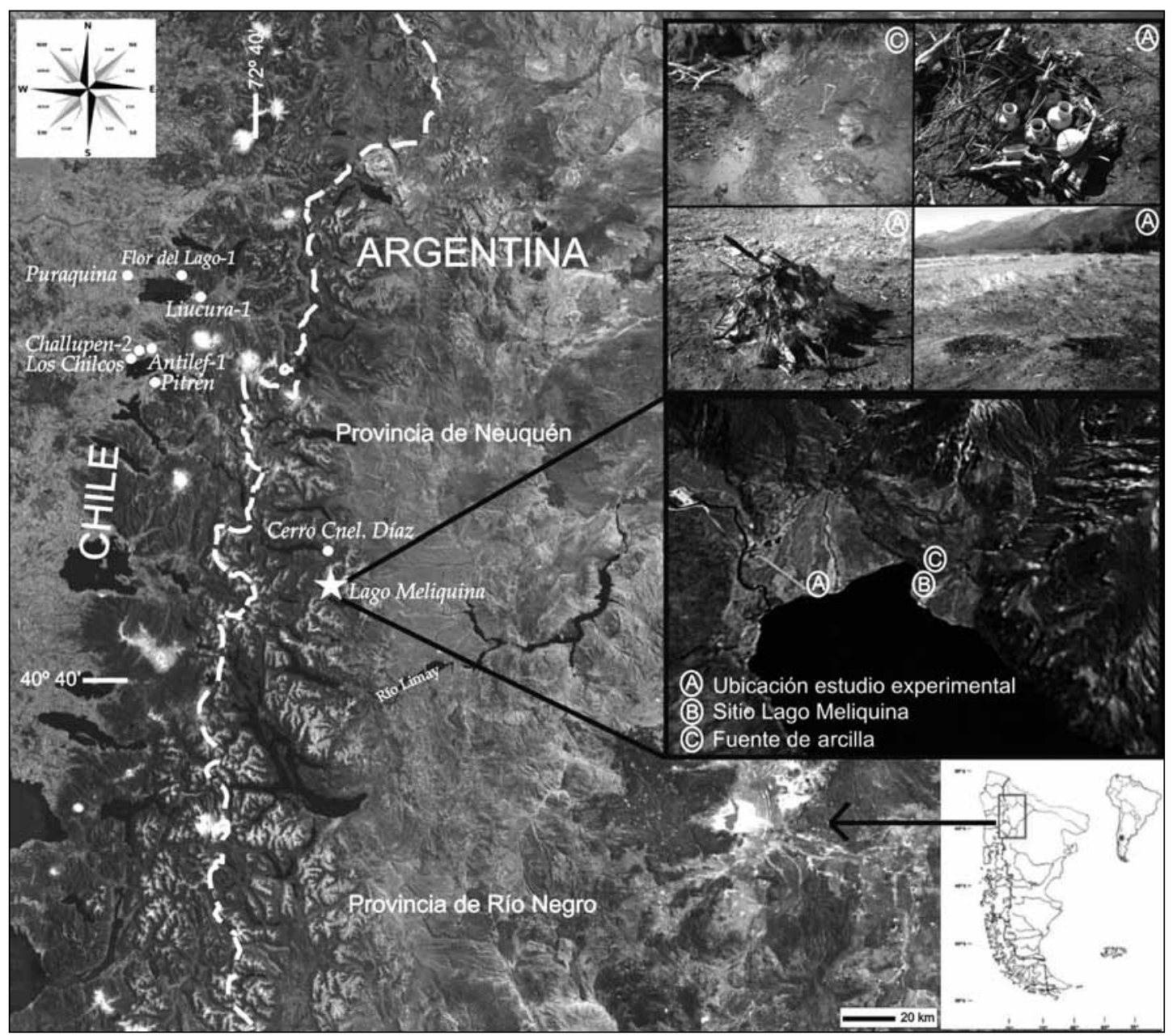

Figura 1. Distribución de alfarería con improntas de hojas y ubicación de estructuras experimentales: (a) sitio Lago Meliquina (b) y fuente de arcilla utilizada para el experimento (c).

Distribution of pottery with leaf imprinting and location of experimental structures: (a) Lake Meliquina site (b) and clay source used for the experiment (c). 
portadores (morfología, decoración, tecnología, etc.). Esto se daría además, en momentos concordantes con un extenso período de inestabilidad ambiental entre los años 800 d.C. y 1.400 d.C., cuyas consecuencias son variadas, aunque aún poco conocidas. Posiblemente algunos episodios de sequía que caracterizan este período hayan servido como un catalizador para la determinación de la territorialidad, la presencia de violencia interpersonal, la migración o el cambio de una estrategia de subsistencia por otra entre poblaciones en competencia por los mismos recursos y con una misma forma de vida. Pero también pudo estimular la mayor interacción entre poblaciones con formas de vida o estrategias adaptativas diferentes (productores v/s apropiadores de recursos, por ejemplo), la intensificación de alianzas y redes sociales incluso a grandes distancias, parte de cuya evidencia podría ser el caso de la presencia de artefactos El Vergel-Valdivia en la región pampeana hace ca. de 800 años a.p. (Berón 2007; Pérez 2011).

\section{Planteamiento del Problema}

No existe un consenso entre los investigadores acerca del origen de los atributos denominados "improntas de hojas" en negativo, en cuanto a que corresponden a una técnica decorativa, o bien, son el resultado involuntario y/o accidental de la cocción de los ceramios. Por ende, a nuestro juicio era necesario saber si se trataba o no del primer caso, ya que despejar esta interrogante permite profundizar en aspectos sobre la tecnología y la territorialidad que las sociedades cazadoras recolectoras portadoras de estos tipos de cerámicas habrían compartido a escala macrorregional. Entonces, nuestro objetivo es tratar de caracterizar tecnológica y sistemáticamente estas modificaciones superficiales de la alfarería. Así, partimos de la hipótesis de que las improntas evidentes de hojas en negativo podrían corresponder a una modalidad estilística regional y singular de los ambientes boscosos templados de la Patagonia Noroccidental Argentina y del Centro Sur de Chile y por ende, no se trataría en forma directa de un producto de la equifinalidad, ni de una acción involuntaria producto de alguna de las etapas del proceso de manufactura cerámica. Para contrastarla propusimos un estudio experimental orientado a evaluar las dos posibles situaciones que podían generar este rasgo tecnológico. La primera era aquella en que las modificaciones superficiales hubiesen sido producidas mediante algún tipo de intervención consciente dentro del proceso de manufactura cerámica o posterior al mismo, como el agregado deliberado o la exposición intencional a agentes (naturales y artificiales) para la modificación de la superficie. Esta intervención estaría orientada a obtener una variación cromática de la superficie de carácter visible y duradero. La segunda situación era aquella en que las modificaciones superficiales hubiesen sido producidas durante la cocción de la alfarería, ya sea por contacto, saturación, oxidación, ahumado o cualquier otra causa natural y no intencional, que hayan implicado la adherencia sobre la superficie de las vasijas de las hojas que formaban parte del combustible para la cocción.

\section{Antecedentes sobre Estudios Experimentales de Alfarería en Patagonia Noroccidental}

Las referencias a estudios experimentales sobre alfarería Patagónica son muy escasas, predominando menciones de carácter descriptivo de los hallazgos donde generalmente los artefactos son utilizados como indicador cronológico-estratigráfico para crear y separar componentes culturales, niveles, etc. (Arrigoni 2002). Generalmente los datos acerca de artefactos cerámicos son presentados como apéndice de artículos donde el mayor énfasis está puesto en los artefactos líticos u óseos. Sobre el problema que nos ocupa, podemos mencionar las observaciones de Schobinger (1969) sobre la descripción de la posible técnica resistente empleada para alfarería modelada y pintada de la provincia del Neuquén. Por su parte, se cuenta con los estudios, análisis y tratamientos que Fernández (1988-90) realizara sobre tiestos de Cueva Chenque Haichol, departamento de Las Lajas, donde aplicó diversos análisis fisicoquímicos sobre tiestos pintados en negativo. Similarmente, Hajduk (1978) describe la experimentación en laboratorio para reproducir la técnica utilizada para la pintura resistente en su trabajo clásico sobre alfarería recuperada en Aluminé y Añelo, en Neuquén. Años más tarde, Arrigoni (2002) realiza la primera descripción sobre un experimento orientado a reproducir las condiciones de las arcillas de fuentes naturales del Parque Nacional Los Alerces para la manufactura de alfarería. En este trabajo describe la calidad de las pastas y combustibles, reproduce alfarería arqueológica y compara resultados experimentales con datos arqueológicos del valle del río Desaguadero, Chubut. 
Sobre la modificación superficial o decorativa de la alfarería, podemos resumir los trabajos regionales entre los que han caracterizado a las técnicas decorativas que implican remoción o desplazamiento del material arcilloso (incisiones y/o grabados) como característico del registro arqueológico norpatagónico (Bellelli 1980; Arrigoni 2002), de aquellas descripciones de alfarería con pintura resistente bastante frecuentes en la provincia de Neuquén (Bellelli 1980), pero cuya producción ha sido atribuida a un origen transcordillerano (Aldazabal et al. 2009; Arrigoni 2002; Fernández 1988-90; Hajduk 1978; Silveira 1996). Respecto de estas últimas, para este trabajo simplemente dividimos a grandes rasgos en forma operativa las modalidades pintura resistente formando diseños geométricos y modelados geométricos de aquellas que presentan improntas de hojas en negativo. Todas ellas han sido integradas como parte del complejo alfarero Pitrén y si bien fueron descritas originariamente para la región Centro Sur de Chile (Adán y Alvarado 1999), son cada vez más comunes en la banda oriental cordillerana a similares latitudes (Aldazabal et al. 2009; Pérez y Reyes 2009; Pérez 2010, 2011). Respecto a la cronología de la alfarería patagónica, la fuente más antigua cercana corresponde a Alero Los Cipreses I, que arroja una datación de 1.510 años a.p. (Silveira 1996), casi contemporánea al inicio de la alfarería en la vertiente occidental cordillerana ca. 1.700 años a.p. (Aldunate 1989; Dillehay 1990). Las alfarerías con improntas de hojas recuperadas en el sitio Lago Meliquina, en San Martín de los Andes, fueron datadas entre 900 y 750 años a.p. (Pérez y Reyes 2009; Pérez 2010).

$\mathrm{Si}$ bien las experimentaciones argentinas se han centrado en la alfarería con decoración grabada e incisa (Arrigoni 2002) y en la variedad pintura resistente -aunque esta última no incluye a las improntas de hojas- (Fernández 1988-90; Hajduk 1978), brindaremos algunos detalles de la modalidad pintada. Esto se debe a que más adelante postularemos que ambas variantes conforman una técnica común ya descrita como negativa (Castro y Varela 1990; Adán y Alvarado 1999), pero que de acuerdo a los estudios ceramológicos modernos, correspondería a lo que en adelante denominaremos "técnica de reserva". Esta última, es de amplia distribución en el continente americano y es escasamente conocida para la región. Según Fernández, la técnica de decoración resistente y sus variedades ha sido muy discutida, permaneciendo algunas sujetas a controversia. En este sentido, él observa que existen algunos puntos que no han podido ser explicados satisfactoriamente, entre ellos la composición de la pintura resistente presuntamente necesaria. Ésta sería aplicada en forma provisoria y removida durante una etapa de tratamiento final (Fernández 1988-90:409), a modo de una sustancia impermeabilizante temporaria o protectora (Hajduk 1978:110). Fernández no acepta el uso de material orgánico como las ceras (disponibles en la región), ya que se volatilizan sin dejar residuos, o proveen un tiznado parejo, aunque Hajduk no lo descarta para alguna de las variantes que propone como aplicables por ahumado (Hajduk 1978:110). En concordancia, tanto Fernández (1988-90), Castro y Varela (1990), Schobinger (1969) y Hajduk (1978) postulan que se trataría de la aplicación de una arcilla removible y a la técnica la denominan "pintura resistente" (Hajduk 1978). Hajduk describe la posibilidad de varias exposiciones a temperatura, donde luego de aplicada la pintura resistente se cubren las piezas con una sustancia orgánica que al ser sometida nuevamente a temperatura se carboniza, dando así, por ejemplo, el color negro característico. Otra explicación posible del color negro es a través del ahumado de las piezas. De este modo considera que los ceramios han sido expuestos dos veces a la acción del fuego (Hajduk 1978:110) y residuos de estructuras de combustión. La primera exposición tiene como objetivo cocer la pasta y la segunda, carbonizar la sustancia orgánica, o ennegrecer los ceramios por ahumado. La temperatura alcanzada en esta última oportunidad seguramente es menor que la alcanzada en la primera, pues a una temperatura mayor se habría producido la pérdida del color negro por volatilización (Hajduk 1978:110).

\section{Breve Descripción de la Técnica Resistente o de "Reserva"}

Desde el punto de vista de la manufactura, la pintura resistente se corresponde con la "técnica de reserva", caracterización aportada por los estudios ceramológicos contemporáneos. La reserva, conocida también como "estarcido" o enmascaramiento es una técnica decorativa. Consiste en reservar, cubrir o enmascarar una parte de la superficie para provocar algún tipo de efecto durante la cocción o recibir otro tipo de decoración. Incluye cualquier medio utilizado para evitar que barbotina, engobes, óxidos o barnices toquen la superficie de la pieza en 
algunos puntos. En resumen, esta técnica engloba diferentes formas de proteger un sector acotado y específico de la superficie de un soporte cerámico para que resista o sobreviva a distintos procesos orientados a alterar la superficie del resto del mismo, obteniendo una variación cromática evidente. La I Convención Nacional de Antropología Argentina (1964) se refiere a la técnica de reserva como pintura negativa, variante pintura de reserva (pp. 34). Para los alfareros, la reserva es una condición necesaria para crear pintura negativa (Fernández Chiti 1997) y que la distingue de un falso negativo, el cual generalmente se realiza por pintado de una figura clara sobre un fondo más oscuro, creando en realidad una figura positiva en lugar de negativa. De este modo, muchas veces se ha confundido el dibujo en negativo y la reserva, ya que ambas técnicas han sido denominadas "pintura negativa". Pese a ello coincidimos en que los diseños negativos que nos interesa estudiar en esta ocasión, ya sea obtenidos por la aplicación de pintura negativa o por efecto de improntas negativas de hojas, parten de una técnica en común, denominada "técnica de reserva". El uso de esta técnica permite unificar a las variantes descritas como pintura negativa e improntas de hojas en negativo, ya que parten de un mismo proceso tecnológico y de un conocimiento compartido muy difundido regionalmente, guardando diferencias sutiles que refuerzan la idea de un "complejo alfarero", a pesar de las aparentes diferencias "estilísticas" internas que caracterizan a la alfarería temprana del centro sur de Chile (Aldunate 1989; Adán y Alvarado 1999; Reyes 2010). En el ámbito de la arqueología de norpatagonia el término pintura resistente fue introducido por Adam Hajduk en su trabajo emblemático de 1978. A partir de una definición extraída del manual clásico de Shepard (1976), el autor remite al concepto de estilo positivo y negativo, términos que utiliza con referencia al efecto de la proporción de claridad y oscuridad en la pintura y no a su método de aplicación (Hajduk 1978:109). En este sentido, si hay preponderancia de los valores más oscuros, o si las relaciones normales de valores son invertidas y partes que de ordinario son claras están oscuras y viceversa, el diseño es considerado negativo, mientras el efecto se destaca más cuando la figura y el fondo se diferencian claramente. Siguiendo a Castro y Varela (1990), técnicamente las improntas de hojas en negativo en las vasijas Pitrén fueron aplicadas a través de la técnica resistente mediante la adhesión de hojas como material protector temporario (material resistente), ya sea en la superficie exterior y/o interior de las piezas previamente cocidas en atmósfera oxidante. Luego, la pieza habría sido introducida en una atmósfera saturada en monóxido de carbono con el fin de oscurecer la superficie (ahumado). Así, finalmente, al desprenderse las hojas éstas dejarían su impronta en el área libre de monóxido, manteniéndose allí el color natural de la arcilla cocida. Esto último operaría para las vasijas monocromas, ya que en aquellas vasijas en las cuales se habría aplicado engobe previamente al ahumado, al sacar las hojas sus improntas permitirían conservar zonas con el respectivo engobe. Según estas autoras, corresponde al recurso plástico conocido como "figura-fondo" (Adán y Alvarado 1999; Castro y Varela 1990), el cual permite la configuración de los motivos decorativos que se desean trasmitir, a través del contraste de colores. Por lo tanto, técnicamente esta modalidad implica el conocimiento de complicados procesos productivos para provocar los efectos plásticos deseados (Adán y Alvarado 1999), y por lo mismo es difícil pensar que sea un rasgo provocado por un accidente casual (Castro y Varela 1990).

\section{Aspectos Metodológicos}

Para la contrastación de la hipótesis que guió este estudio se utilizó un modelo experimental tendiente a reproducir y controlar las condiciones naturales para la cocción de la alfarería y algunas modificaciones superficiales postcocción, intentando cuantificar, analizar y describir las variables inherentes. En suma, se indujo a la aparición de las improntas de hojas mediante diferentes formas. Por un lado, algunas vasijas fueron cocidas en ambiente oxidante sin ningún tipo de manipulación, mientras que a otras se les agregaron artificialmente elementos naturales sobre sus superficies cuando todavía se encontraban crudas en estado cuero y luego fueron sometidas a cocción en ambiente oxidante. Por otro, algunas vasijas ya cocidas fueron expuestas a segundas cocciones en atmósferas reductoras y otras a ahumados en ambientes sin incidencia calórica, o sea, sólo exponiendo la pieza a emanaciones de la combustión.

El ceramista especializado en replicación de técnicas y decoraciones alfareras precolombinas Luis Hermann, estuvo a cargo de la parte técnica del experimento, dirigido y asistido por los autores. Se 
manufacturaron nueve soportes (vasijas) utilizando arcillas naturales recolectadas en sectores próximos a los sitios arqueológicos donde abunda la alfarería. Los soportes fueron manufacturados por rodete y por vaciado (molde con barbotina) con molde de yeso. Los soportes fueron trabajados en forma completa, en algunos casos utilizándolos perimetralmente y en otros casos subdividiéndolos en máximo dos sectores para aplicar pruebas diferentes sobre el mismo. El material natural agregado correspondió a hojas de vegetales nativos, arcilla líquida (barbotina), minerales similares a los encontrados en las cerámicas arqueológicas, plumas, hisopos con pelo de ciervo y roedores. Para el ahumado se utilizó el remanente natural de la combustión de aceites vegetales y grasa animal. El combustible utilizado correspondió a madera y hojas de ñire (Nothofagus antarctica), muy abundante en los sitios estudiados y reconocida como excelente para la combustión requerida. Como material de ignición (yesca) se utilizó caña de colihue seca (Chusquea culeau) y hojas de ñire y abedul (Betula péndula). Para la combustión se emplazaron dos estructuras a cielo abierto para lograr una cocción oxidante, similar a la observada en las piezas arqueológicas recuperadas localmente. Sobre uno de los soportes experimentales se realizó una segunda cocción más reductora, utilizando saturación de hojas, incluyendo un 50\% humedecidas. Además, una de las muestras previamente cocida fue expuesta a ahumado por contacto indirecto con la combustión de aceite vegetal y grasa animal. Una vez concluida cada etapa y proceso de trabajo, se procedió a la descripción de las superficies de las piezas.

\section{Experimentación}

\section{Experimento 1/Estructura 1: Cantidad de vasijas 7}

Características de la intervención realizada sobre las superficies de las vasijas: muestras 1, 2, 3, 4, 5, 6 y 9 (ver descripción Tabla 1 y Figura 2). Emplazamiento: valle de doña Mica. Cielo abierto, $200 \mathrm{~m}$. de lago Meliquina. Temperatura ambiental: $15-17^{\circ} \mathrm{C}$. Viento: moderado del Oeste. Combustible: $23 \mathrm{~kg}$. Madera de ñire seco y yesca. Yesca: caña colihue y hojas de ñire. Ignición: 14:20 hrs. Viento leve ayuda a encender; $14: 25 \mathrm{hrs} .500{ }^{\circ} \mathrm{C}$; $14: 27$ hrs. $750^{\circ} \mathrm{C} ; 14: 30$ hrs. $860^{\circ} \mathrm{C}$. Extinción natural: 15:20 hrs.

\section{Experimento 2/Estructura 2: Cantidad de vasijas 2}

Características de la intervención realizada sobre las superficies de las vasijas: muestras 7 y 8 (ver descripción Tabla 1 y Figura 2). Emplazamiento: valle de doña Mica. Cielo abierto, $200 \mathrm{~m}$ de lago Meliquina. Temperatura ambiental: $15-17^{\circ} \mathrm{C}$. Viento: moderado del Oeste. Combustible: $22 \mathrm{~kg}$. Madera de ñire, hojas de ñire y abedul. Yesca: caña colihue y hojas de ñire. Ignición: 15:20 hrs. Viento leve ayuda a encender; $15: 22$ hrs. $700{ }^{\circ} \mathrm{C}$; 15:25 hrs. $900{ }^{\circ} \mathrm{C}$. Extinción natural: 16:20 hrs. Observaciones: Temperatura fluctuante entre 670 y $850{ }^{\circ} \mathrm{C}$ por viento. Después de 7 minutos de la ignición se mantiene por encima de los $650{ }^{\circ} \mathrm{C}$.

\section{Experimento 3/ Reutilización de estructura experimental 1: Cantidad de vasijas 1}

Características de la intervención realizada sobre las superficies de las vasijas:

Tabla 1: reutilización de muestra 7 (ver descripción Tabla 1 y Figura 2). Segunda cocción tipo reductora. Se pintan motivos en forma de hojas con barbotina y se deposita en el centro de la estructura experimental 1 ya extinta. Se cubre con hojas de abedul húmedo y de ñire seco, $7 \mathrm{~kg}$. de hojas. Se procede a la ignición, la cual dura 26 minutos hasta extinguirse.

\section{Experimento 4: Cantidad de vasijas 1}

Características de la intervención realizada sobre las superficies de las vasijas: reutilización de muestra 8 (ver descripción Tabla 1 y Figura 2). Exposición de vasija previamente cocida en experimento 1 , utilizando la muestra 8 . Se cubre con hojas de fresa silvestre (Fragaria sp.), adheridas con arcilla líquida y grasa animal. Se coloca la vasija en suspensión un metro sobre la estructura de combustión experimental 1, compuesta en esta ocasión de hojas y ramas de ñire, sobre la cual se vierte aceite de cocina industrial y luego grasa de ciervo colorado. La exposición dura aproximadamente 30 segundos. Luego se retiran las hojas de fresas y se limpia con hojas frescas la superficie de las vasijas, removiendo una gran cantidad de hollín de la superficie descubierta. Se procede al posterior lavado con agua y fricción manual de la vasija. 


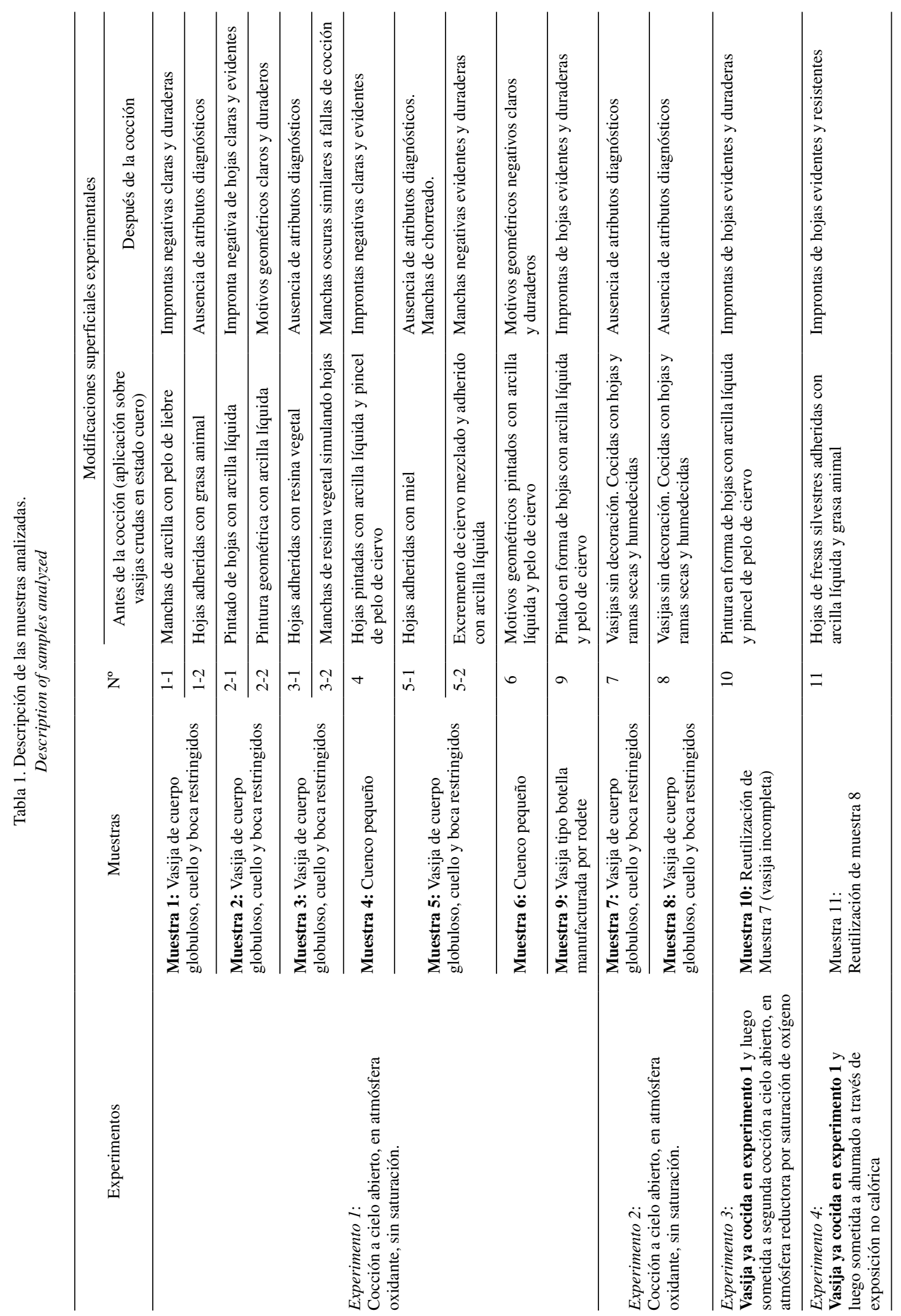




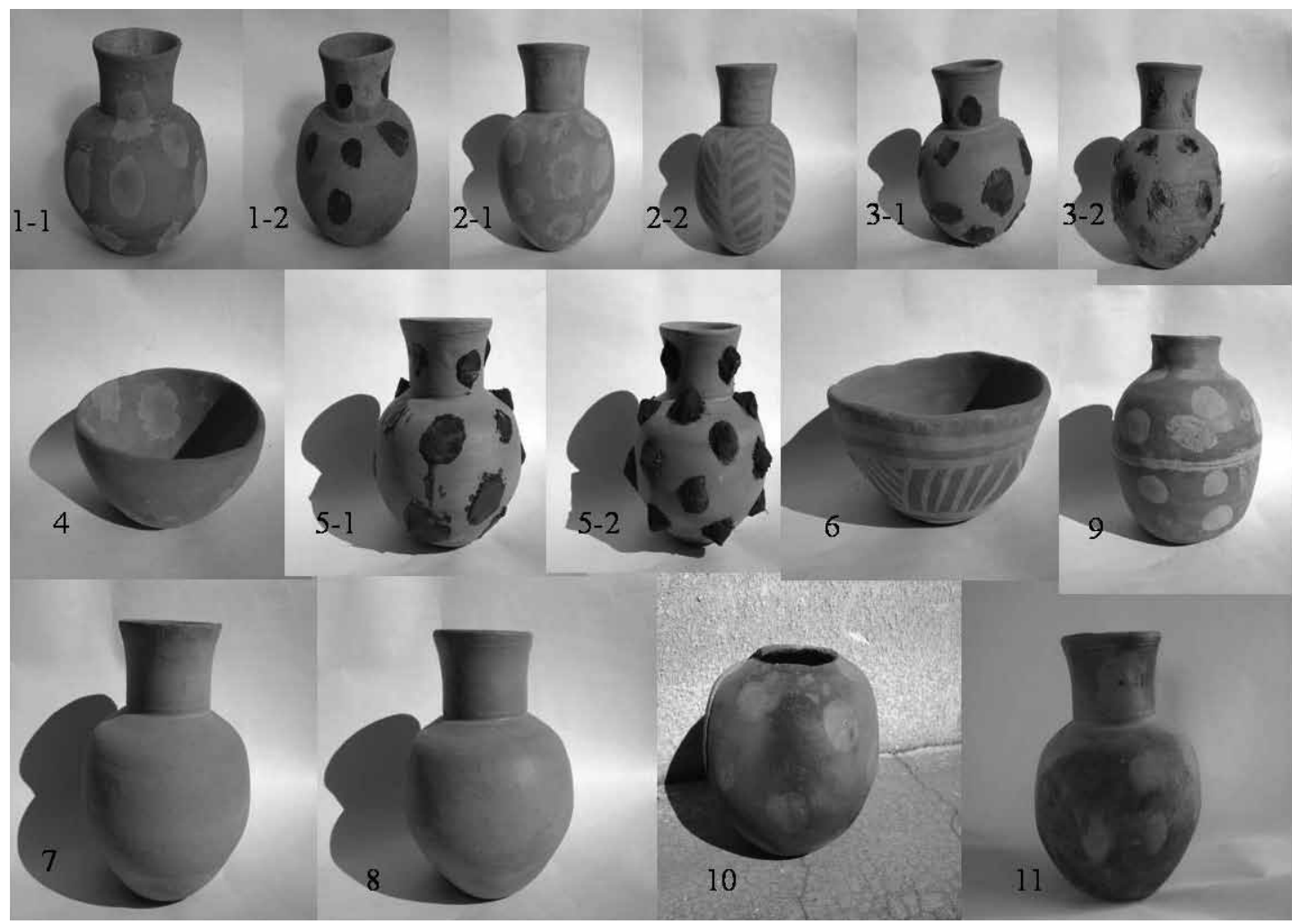

Figura 2. Vasijas obtenidas de la experimentación. Vessels obtained from the experiment.

\section{Resultados y discusión}

Los resultados del estudio experimental muestran que en cuanto al combustible disponible, el ñire (Nothofagus antarctica), abundante en el área, resultó tener cualidades excepcionales y su uso coincide con los datos aportados por un informante nativo local acerca de las cualidades de distintas maderas para la combustión (Sr. Elesto Panguilef com. pers. 2010). Se pudo obtener en todos los experimentos temperaturas superiores a los $900{ }^{\circ} \mathrm{C}$ y un promedio entre 650 y $690{ }^{\circ} \mathrm{C}$ por más de 30 minutos después de la primera media hora de la ignición, y casi hasta pocos minutos después de la extinción natural del mismo. Respecto a los objetivos propuestos para este trabajo, podemos decir que del estudio experimental se comprobó que los atributos denominados "improntas de hojas" son rasgos inducidos intencionalmente y por ende caracterizables como una "modalidad estilística". Esto se desprende del análisis de las experimentaciones realizadas, ya que las modificaciones superficiales similares a hojas en negativo no pudieron ser obtenidas como producto involuntario de la cocción, ya sea causadas naturalmente por oxidación, contacto, saturación de combustión o ahumado (ver Tabla 1, experimento 2, muestras 7 y 8). Estas sólo pudieron ser reproducidas por medio de la intervención antrópica dirigida, a partir del agregado de una sustancia cobertora temporárea, tanto durante la primera cocción (Tabla 1, experimento 1, muestras 1-1, 2-1, 4 y 9 y motivos geométricos pintados en las muestras 2-2 y 6), como mediante la exposición a una segunda cocción de características más reductoras (Tabla 1, experimento 3, muestra 10). Sin embargo, pudimos reproducir también improntas negativa de hojas durante un proceso de exposición indirecta al agente térmico, ahumando la pieza (Tabla 1, experimento 4, muestra 11). En este caso, las hojas fueron adheridas con arcilla líquida y con grasa animal, como sustancia adherente. Ambas pruebas resultaron positivas, ya que las hojas y el material orgánico adherente (además del arcilloso) permanecieron sin alterar su estructura ni ubicación 
durante el breve pero efectivo tiempo de exposición al ahumado. Lo que llamamos una exposición indirecta controlada y no calórica. Estos resultados tienen interesantes implicancias para entender los procesos de manufactura de las vasijas negras sobre engobe colorado y de las monocromas con impronta de hojas. Por un lado, las hojas en sí mismas no constituyen un material resistente adecuado para la exposición directa a la combustión, ya que el calor las destruye invisibilizando su rastro y volatilizando cualquiera de las sustancias orgánicas utilizadas experimentalmente para mantenerlas adheridas. La exposición directa entonces requiere de alguna sustancia como arcilla, resistente a la temperatura y posteriormente fácil de remover. Lo mismo que durante la exposición indirecta (experimento 4), o sea mediante el ahumado sin exposición al calor, en el cual también las hojas constituyeron el material protector o reservante resistente, las cuales fueron adheridas tanto con barbotina como con grasa animal. De nuestro caso experimental, dirigido a la reproducción de hojas negativas, observamos cómo los materiales orgánicos como hojas, resina vegetal, grasa animal y cera vegetal se funden hasta volatilizarse a temperaturas bajas pero prolongadas durante una exposición directa a la combustión. Las únicas pruebas que resultaron positivas corresponden a las que en forma directa (aplicado por isopado o pincelado) o indirecta (hojas y excremento impregnado) contenían arcilla líquida como principal sustancia cobertora, ya sea durante las cocciones oxidantes y reductoras o bien mediante la exposición no calórica a la combustión, como sería el caso del ahumado de las vasijas con sus superficies reservadas con hojas. Las arcillas en forma líquida, por su cualidad temperante y resistente a los cambios de temperatura, aplicadas sobre un soporte también arcilloso pero seco -alisado y/o pulido-, se constituye en un material resistente a la cocción sin ligarse o fusionarse al soporte, brindando una exposición diferencial a la temperatura en el sector cubierto, el cual una vez cocido puede ser removido en su totalidad en forma sencilla, dejando una impronta negativa en la zona reservada. Esta podría ser la técnica utilizada para la modalidad negra sobre engobe colorado. Estos resultados nos permiten postular como hipótesis que las vasijas con decoración negra sobre engobe colorado han sido manufacturadas mediante un proceso de dos etapas, la primera es la elaboración y cocción de una pieza engobada en rojo, para pasar a una segunda etapa, que consiste en reservar partes de la pieza ya cocida con un material resistente temporáneo, el cual pudo ser por nuestra experimentación preferentemente arcilloso (liquido, sólido o algún material embebido en ésta), para ser sometida a continuación a una segunda modificación. Aún no sabemos con certeza si esta última se trata de una nueva alteración utilizando una estructura de combustión, ya sea mediante una exposición de tipo directa al agente calórico que pudo ennegrecer por reducción el sector no reservado, o quemando alguna sustancia orgánica agregada a este sector no reservado, o finalmente mediante exponer la pieza al ahumado. El uso de reservas, entonces, permite, unificar a las variantes descritas como pintura resistente (negativa) formando motivos decorativos geométricos e improntas de hojas, ya que parten de una misma técnica.

Deseamos aclarar que no se trata de una técnica estandarizada y que la misma guarda importante variación interna. Su gran variabilidad puede resumirse en forma aproximada entre aquellas que guardan rasgos muy notorios, de carácter naturalista, de aquellas más esquemáticas que aparentan simples manchas, pero que guardan una presencia y frecuencia que denota su intencionalidad. Sabemos gracias a nuestro estudio experimental, que se pueden obtener éstas tanto de la aplicación de las hojas embebidas en arcilla líquida, como por medio de manchas de arcilla aplicadas con hisopos y de la pintura de ellas. Las dos últimas no necesariamente implican el uso de hojas, sino simplemente la reproducción de las mismas. Además, mediante el ahumado pueden obtenerse negativos de hojas expeditivamente, en forma casi instantánea, y sin necesidad de realizar una cocción especial para tal fin.

Una de las características reconocidas etnohistóricamente de los grupos mapuche es el uso de sustancias químicas de origen animal y vegetal, mediante la extracción de toxinas y su procesamiento para producir medicinas, sustancias alucinógenas y venenos (Mera y Lobos 2008 en Pérez 2010, 2011). Es posible entonces que hayan existido vasijas de uso restringido para producir y contener sustancias tóxicas, y que las mismas fueran identificadas macroscópicamente para evitar la intoxicación involuntaria. De esta manera, postulamos como hipótesis que pudo haber existido una utilización de recipientes para fines específicos, como por ejemplo contener ciertas sustancias tóxicas. Estos recipientes pudieron ser distinguidos ex profeso ya sea por 
características formales necesarias, para resaltar el valor o la importancia social del contenido y/o para evitar el consumo involuntario o accidental de sustancias tóxicas, separándolas de aquellas vasijas utilitarias. Estas últimas eventualmente pudieron haber servido para procesar alguna sustancia tóxica, cuyo carácter relictual desconocido las separaría desde ese momento de otras funciones, requiriendo desde entonces de una marca distintiva para evitar intoxicaciones involuntarias (Pérez 2011). Este último bien puede ser el caso de las improntas de hojas aplicadas mediante una segunda exposición calórica con partes reservadas, similar al experimento $3, y / o$ incluso más expeditivamente, exponiéndolas a un sencillo proceso de ahumado como recreamos en el experimento 4. Mientras que, en el caso de vasijas con diseños bicromos negro sobre colorado y otras con representaciones modeladas de anfibios, podrían estar vinculadas a la producción y uso exclusivo y anticipado de sustancias altamente tóxicas, como venenos y alucinógenos.

Recapitulando podemos señalar que las improntas de hojas en negativo, manufacturadas a través de la técnica de "reserva", son un rasgo tecnológico que indiscutiblemente forma parte de los aspectos externos y evidentes de las vasijas Pitrén. Siguiendo los postulados teóricos del estilo tecnológico, podemos decir que la técnica de "reserva" de improntas de hojas en negativo puede ser interpretada como parte de aquellas elecciones tecnológicas de manufactura cerámica que fueron visibles y se "leyeron" en el producto final (las vasijas terminadas). Por lo tanto, sus alfareros pudieron haber manipulado y transmitido este conocimiento tecnológico conscientemente en situaciones post-aprendizaje cerámico (Gosselain 1998). En este sentido, es loable pensar que detrás de esta técnica debieron subyacer una serie de códigos visuales e ideas (Gosselain 1998) que le dieron sentido y que además fueron compartidos por diversos grupos que abarcaron una amplia distribución territorial, la cual para el período alfarero incluiría ambas vertientes de la cordillera andina.

Agradecimientos: En primera instancia se agradecen los comentarios y correcciones de los evaluadores, ya que sin duda enriquecieron el contenido de este escrito. Este trabajo forma parte del proyecto UBA 840162, Arqueología del bosque meridional neuquino y su relación con sitios del área Paso Limay, estepa rionegrina y sectores transicionales, y del proyecto $\mathrm{N}^{\circ} 834$ de APN. Los autores son los únicos responsables de los comentarios expuestos.

\section{Referencias Citadas}

Adán, L. y M. Alvarado 1999. Análisis de colecciones alfareras pertenecientes al complejo Pitrén: Una aproximación desde la arqueología y la estética. Soplando en el viento... Actas de las III Jornadas de Arqueología de Patagonia, pp. 245-268. Instituto Nacional de Antropología y Pensamiento Latinoamericano y Facultad de Humanidades, Universidad Nacional del Comahue, Neuquén-Buenos Aires.

Aldazabal, V., M. Silveira y A. Micaelli 2008-2009. La cerámica del sitio Alero Las mellizas, Lago Traful, Provincia de Neuquén. Anales de Arqueología y Etnología 63-64:1-24.

Aldunate, C. 1989. Estadio alfarero en el sur de Chile. En Culturas de Chile. Prehistoria. Desde sus Orígenes hasta los Albores de la Conquista, editado por J. Hidalgo, V. Schiappacasse, H. Niemeyer, C. Aldunate e I. Solimano, pp. 329-348. Andrés Bello, Santiago.

Arrigoni, G. 2002. Los ceramistas prehistóricos del valle del Río Desaguadero, Parque Nacional Los Alerces, provincia del Chubut. Relaciones de la Sociedad Argentina de Antropología XXVII:395-412.

Bellelli, C. 1980. La decoración de la cerámica gris incisa de la Patagonia, República Argentina. Revista del Museo Paulista XXVII: $199-225$.
Berón, M. 2007. Circulación de bienes como indicador de interacción entre las poblaciones de la pampa occidental y sus vecinos. Arqueología en las Pampas vol. I:345-364.

Castro, V. y V. Varela 1990. Artífices del Barro. Museo Chileno de Arte Precolombino y Banco O'Higgins, Santiago.

Dillehay, T. 1990. Araucanía, Presente y Pasado. Editorial Andrés Bello, Santiago.

Fernández, J. 1988-1990. La cueva de Haichol. Arqueología de los pinares cordilleranos del Neuquén. Anales de Arqueología y Etnología 43-45:103-114.

Fernández Chiti, J. 1997. Cerámica Indígena Arqueológica Argentina. Las Técnicas, los Orígenes, el Diseño. Ediciones Condorhuasi, Buenos Aires.

Gambier, M. 1964. Primera Convención de Córdoba: nomenclatura de las piezas cerámicas, Instituto de Arqueología de San Juan, Argentina. Manuscrito en posesión del autor.

Gosselain, O. 1998. Social and technical identity in a clay crystal ball. En The Archaeology of Social Boundaries, editado por M. Stark, pp. 78-106. Smithsonian Institution Press, Washington.

Hajduk, A. 1978. Excepcionales ceramios de la provincia del Neuquén. Presencia de alfarería con decoración por pintura 
resistente en la provincia de Neuquén. Algunas consideraciones en torno a ella. Revista del Museo Provincial 1:103-121.

Pérez, A. y V. Reyes 2009. Técnica improntas de hojas. Algunas reflexiones acerca de su novedoso registro en la vertiente occidental cordillerana. Revista Magallania 37:113-132.

Pérez, A. 2010. La Mirada de Ngenechen. Representaciones anfibiomorfas en la alfarería de la Patagonia Noroccidental Argentina. Comechingonia 12:99-112.

- - - 2011. Algunas reflexiones sobre la alfarería del CentroSur de Chile y ambientes lacustres precordileranos de la Patagonia Septentrional Argentina. En Cultura y Espacio. Araucanía-Norpatagonia, editado por P. Navarro y W. Delrio, pp. 293-311. Editorial Universidad Nacional de Río Negro, Río Negro.

Reyes, V. 2010. Microvariaciones en la cerámica de sitios alfareros tardios de dos cuencas lacustres precordilleranas de la
Araucanía: lagos Villarrica y Calafquén, IX y XIV regiones de Chile. Memoria para optar al título de arqueólogo, Departamento de Antropología Facultad de Ciencias Sociales, Universidad de Chile, Santiago.

Rye, O. 1981. Pottery Technology. Taraxacum, Washington D.C.

Silveira, M. 1996. Alero Los Cipreses (Provincia del Neuquén, República Argentina). Arqueología Sólo Patagonia. Actas de las II Jornadas de Arqueología de la Patagonia, editado por J. Gómez Otero, pp. 107-118. Centro Nacional Patagónico, Puerto Madryn.

Shepard, A. 1976. Ceramics for the Archaeologist. Carnegie Institution of Washington D.C.

Schobinger, J. 1969. Un notable cántaro ceremonial antropomorfo de la zona cordillerana del Neuquén (Argentina). Actas del V Congreso Nacional de Arqueología de Chile, pp. 377-387. Museo Arqueológico de La Serena, La Serena. 
